\title{
Variations in antimalarial components of Artemisia annua Linn from three regions of Uganda
}

\author{
Patrick Ogwang Engeu², Francis Omujal', Moses Agwaya ${ }^{1}$, Hassan Kyakulaga ${ }^{3}$, Celestino Obua. ${ }^{2}$
}

1. Natural Chemotherapeutics Research Institute, Ministry of Health P.O.Box 4864 Kampala, Uganda

2. Faculty of Medicine, Mbarara University of Science \& Technology, P.O.Box 1410, University Road, Mbarara, Uganda.

3. College of Veterinary Medicine, Animal Resources and Biosecurity, Makerere University, P.O.Box 7062 Kampala, Uganda.

\begin{abstract}
Introduction:: Artemisia annua plant from the family Asteracea is a powerful antimalarial plant introduced to Uganda around 2003. In addition to the artemisinin component, the plant also contains flavonoids which work in synergy to artemisinin against malaria parasites. The plant also contains aromatic oils which repel mosquitoes. In this paper we report the variations in antimalarial components of $\mathrm{A}$. annua samples from the regions cultivating it in Uganda.

Methods: Artemisia annua samples were obtained from three regions that cultivated the plant at the time of this study. The samples were brought to laboratory, authenticated and processed. The levels of artemisinin, total flavonoids and aromatic components were quantified using high performance thin layer chromatography, ultra violet spectrophotometry and gas chromatography respectively.

Results: Artemisinin and total flavonoids levels were higher in samples obtained from high land areas (western and south western region) compared to that obtained from lowland regions (central) i.e $0.8 \% \mathrm{Vs} 0.4 \%$ and $2.6 \% \mathrm{Vs} 1.5 \%$ respectively. The aromatic oils (mosquito repellent components) were similar with camphor component being highest and levels ranging from $75.4 \%$ to $79.0 \%$.

Conclusion: Our findings show that the active components in Artemisia annua cultivated and used in the Uganda vary with geographical regions and this calls for standardisation by source.

Key words: Variations, Antimalarial components, Artemisia annua, Uganda

DOI: http://dx.doi.org/10.4314/ahs.v15i3.17

Cite as: Engeu PO, Omujal F, Agwaya M, Kyakulaga H, Obua C. Variations in antimalarial components of Artemisia annua Linn from three regions of Uganda. Afri Health Sci. 2015;15(3):828-34. doi: http:/ / dx.doi.org/10.4314/abs.v15i3.17
\end{abstract}

\section{Introduction}

Artemisia annua $\mathrm{L}$. is a medicinal weed that belongs to the Asteracea family of plants. It is native to Asia especially China but also found in Europe and North America. In China, the leaves were used as infusion to cure malaria and also burnt to repel mosquitoes for over 3000 years ${ }^{1}$. A. annua plant was introduced to Uganda around 2003 as the source of artemisinin needed by the pharmaceutical industries that manufacture Artemisinin combination therapies (ACTs). Ugandan soils

\section{Corresponding author \\ Patrick Ogwang Engeu \\ Natural Chemotherapeutics \\ Research Institute, Ministry of Health \\ P.O.Box 4864 Kampala, Uganda, \\ Tel +256-712-491054, \\ Email: pe7321@gmail.com}

are reported to be suitable for cultivation of A.annua ${ }^{2}$. Artemisinin the most potent antimalarial known or its derivative is not used singly in treatment of malaria but used in combination with other antimalarial drugs. The artemisinin combinations are currently WHO recommended treatments for uncomplicated malaria ${ }^{3}$. Apart from artemisinin, A. annua also contains other antimalarial compounds that work in synergy with artemisinin offering a natural combination therapy against malar$\mathrm{ia}^{4,5,6,7}$.

In Uganda, the cultivation of the plant was initially restricted to farmers in highland areas mainly in western Uganda. However, the drop in the demand for artemisinin from Uganda by the industries that make its derivatives led to uncontrolled and wide spread local cultivation and use of the plant in Uganda. The plant is now cultivated and used by communities in Central, Eastern and Northern Uganda which are low land areas (less than $1200 \mathrm{~m}$ above sea level) initially not recommended for the plant ${ }^{8,9}$. A recent study in Uganda reported that although Ugandan soils are suitable for 
cultivation of artemisinin, artemisinin levels vary with area of cultivation. The variations in levels of other antimalaial components remained unknown until this study. All plant components are known to vary according to geographical locations which in turn may lead to varying clinical outcomes in patients ${ }^{10}$. The low land areas in Uganda have altitude of about $1200 \mathrm{~m}$, receive total rainfall of about $1000 \mathrm{~mm}$ per annum and temperatures of up to $84^{\circ} \mathrm{F}$. The high land areas have altitude of up to $2500 \mathrm{~m}$; receive rainfall of up to $1200 \mathrm{~mm}$ per annum and temperatures of up to $73^{\circ} \mathrm{F}$. In this paper, we report variations in the levels of artemisinin, total flavonoids and aromatic oils in samples from the three regions cultivating A.annua in Uganda.

\section{Materials and methods}

\section{Material collection}

Artemisia annua plant was collected from the Wagagai flower farm garden in Central Uganda in February 2009. The specimen was identified by a taxonomist at Natural Chemotherapeutics Research Institute (NCRI) herbarium, Ministry of Health, Uganda. A voucher specimen, NCJ 257 was deposited at the herbarium of NCRI for use as reference. Dry leaf powder of A. annua samples $(1 \mathrm{~kg})$ was also obtained from Wagagai health clinic, where it has been used as tea for malaria prophylaxis among the farm workers since $2006^{9}$. Other dry leaf powder samples ( $1 \mathrm{~kg}$ each) were obtained from the two major commercial cultivators in Uganda located in high land areas i.e Kabale district in south western Uganda and Fortportal district in Western Uganda. The samples brought to the laboratory were stored in air tight opaque containers at room temperatures till the time of analysis.

\section{Phytochemical screening of artemisia annua ma- terials.}

The A.annua dry leaf powders $(100 \mathrm{~g})$ were extracted with soxhlet apparatus in a sequential manner using petroleum ether, followed by ethanol and then methanol solvent. While A.annua tea was prepared by adding boiling water to dry leaf powder to make $10 \mathrm{~g} / \mathrm{L}$ infusion following procedures previously described . Phytochemical ingredients in both leaf powders and tea extracts were determined using methods described in the manual of analysis of vegetable drugs ${ }^{11}$ as briefly described;

\section{Polyuronides}

To a test tube containing ( $10 \mathrm{ml}$ of formulation) was added drops of water, leading to formation of a thick
precipitate.The precipitate obtained was placed on the filter paper and on staining with hematoxylin formed a blue precipitate for presence of polyuronides.

\section{Reducing compounds}

$1 \mathrm{ml}$ of formulation was diluted with water $(2 \mathrm{ml})$ in test tube. Fehling's solutions I (1ml) and Fehling's solution II $(1 \mathrm{ml})$ were added and heated in a water bath at $90^{\circ} \mathrm{C}$ forming a brick-red precipitate.

\section{Saponins}

A diluted solution of the formulation $(2 \mathrm{ml})$ was placed in a test tube and shaken for 15 minutes. A soapy like column of about $2 \mathrm{~cm}$ formed above liquid level.

\section{Tannins}

To the formulation $(1 \mathrm{ml})$ was added water $(2 \mathrm{ml})$ and 3 drops of ferric chloride. A blackish blue color formed.

\section{Alkaloid salts}

The formulation $(15 \mathrm{ml})$ was evaporated to dryness in an oven at $55^{\circ} \mathrm{C}$ and residue dissolved in $10 \% \mathrm{v} / \mathrm{v} \mathrm{Hy}-$ drochloric acid $(10 \mathrm{~mL}) .10 \% \mathrm{v} / \mathrm{v}$ ammonia solution $(10 \mathrm{ml})$ was added to precipitate the alkaloids and then extracted with ether $(15 \mathrm{ml})$. The ether portion was evaporated to dryness and hydrochloric acid $(1.5 \mathrm{ml})$ added. To $0.5 \mathrm{ml}$ of the acidic solution was added 2-3 drops of Mayer's reagents forming opalescence precipitate.

To detect Steroid glycosides, Anthracenosides, coumarins and flavonosides, $25 \mathrm{ml}$ of the formulation was mixed in $10 \% \mathrm{v} / \mathrm{v}$ hydrochloric acid $(15 \mathrm{ml})$, refluxed for 30 minutes, cooled and extracted with diethyl ether $(36 \mathrm{ml})$ in portions of $12 \mathrm{ml}$ each.

\section{Steroid glycosides}

To a residue obtained by evaporating to dryness ether extract $(10 \mathrm{ml})$ was added acetic anhydride $(0.50 \mathrm{ml})$ and chloroform $(0.50 \mathrm{ml})$ and transferred into a dry tube. Conc. Sulphuric acid $(2 \mathrm{ml})$ was added by means of a pipette at the bottom of the tube forming reddish-brown ring at the contact zone of the two layers.

\section{Anthracenosides}

The ether extract $(4 \mathrm{~mL})$ was added to conc. Sulphuric acid $(2 \mathrm{~mL})$ and shaken with $25 \% \mathrm{v} / \mathrm{v}$ ammonia solution $(2 \mathrm{ml})$ forming cherished-red solution on the top layer.

\section{Coumarin derivatives}

To a residue obtained by evaporating ether extract ( 5 
$\mathrm{mL})$ was added hot water $(2 \mathrm{ml})$ to dissolve. $10 \% \mathrm{v} / \mathrm{v}$ ammonium solution $(0.5 \mathrm{ml})$ was then added forming a blue fluorescence solution under UV.

\section{Flavonosides}

The residue obtained by evaporating ether extract $(5 \mathrm{ml})$ was heated in $50 \%$ methanol $(2 \mathrm{~mL})$. Metallic magnesium ( $0.5 \mathrm{~g}$ ) and conc. Hydrochloric acid (5drops) was added forming a red solution.

\section{Aromatic oil profile in artemisia annua materials.}

The aromatic oils were extracted by hydro-distillation of $500 \mathrm{~g}$ of $\mathrm{A}$. annua dry leaf powder. The distillate was cooled and fractionated with petroleumether $(500 \mathrm{ml})$ to extract the volatile oils. The oils in the ether fraction were analysed using Shimadzu GC-MS; model, C70374300170. The peak area of each component of the oil was identified through the in built database and content of each identified component computed based on peak areas as percentages.

Determination of artemisinin content in the artemisia annua samples

\section{Construction of artemisinin calibration curve}

Method previous described for quantification of artemisinin in bulk forms was adopted ${ }^{12}$. Pure artemisinin $(1 \mathrm{mg})$ donated by African Laboratory for Natural Products (ALNAP) in Ethiopia was dissolved in ethanol to make $100 \mathrm{ml}$ stock solution. Concentrations of 200ng/ $\mathrm{ml}, 300 \mathrm{ng} / \mathrm{ml}, 500 \mathrm{ng} / \mathrm{ml}$ and $1000 \mathrm{ng} / \mathrm{ml}$ of pure artemisinin were applied onto Thin Layer Chromatographic (TLC) plate ( Merck) by the automated High Perfomance Thin Layer Chromatography (HPTLC) applicator, the plate was developed in HPTLC chamber using solvent system consisting of Heptane- diethyl ether in the ratio1:1. The plate after drying was dipped into Acetic acid- H2SO4- Anisaldehyde (10:0.02:0.1) solvent to derivatise the artemisinin. The retardation factor (Rf) value for artemisinin was 0.5. After drying, the absorbances for each concentration was measured at $366 \mathrm{~nm}$ UV-wave length utilising radiation source combining Deuterium (D2) and tungstem lamps. The concentrations and absorbances were used to construct the calibration curve giving line of best fit R2 $=0.99999$ (Figure 1)

\section{Quantification of artemisinin in dry leaf powder and tea}

Artemisia annua dry powder samples (1g) was extracted in $10 \mathrm{mls}$ of $\mathrm{n}$-toluene in sonicator for 45 minutes. The extract was filtered through a whatmann filter (No.1).
Extract was then applied onto Thin Layer Chromatographic (TLC) plates (Merck) by the automated High Perfomance ThinLayer Chromatography (HPTLC) applicator. The plate was developed in HPTLC chamber using solvent system, heptane- diethyl ether (1:1) and derivatised as described above in 2.4.1. The absorbance was measured at $366 \mathrm{~nm}$ UV-wave length and artemisinin content obtained from the calibration curve shown. The concentration of artemisinin in A.annua tea was determined using the same procedures.

\section{Determination of total flavonoids in the Artemisia annua samples}

\section{Construction of casticin calibration curve}

Casticin is one of the antimalarial and immunomodulatory flavonoids present in A.annua that works in synergy to artemisinin. The method previously described by Chen et al for determination of total flavonoids was adopted with slight modification ${ }^{13}$. Casticin used as a standard was prepared by dissolving $14 \mathrm{mg}$ in $25 \mathrm{mls}$ of $70 \%$ ethanol to give a concentration of $0.56 \mathrm{mg} / \mathrm{ml}$. The standard $(4 \mathrm{ml})$ was then pipetted into $10 \mathrm{mls}$ volumetric flask and $0.4 \mathrm{mls}$ of $5 \% \mathrm{NaNO}_{2}$ added, mixed and allowed to react for 6 minutes. A solution of $10 \%$ $\mathrm{Al}\left(\mathrm{NO}_{3}\right) 3(0.4 \mathrm{ml})$ instead of $\mathrm{AlCl}_{3}$ previously used by Chen et al was added, mixed and allowed to complex for 6 minutes before adding $4 \mathrm{mls}$ of $4 \% \mathrm{NaOH}$ to neutralise the acidity. Double distilled water was added to top to the $10 \mathrm{mls}$ mark giving a yellow green solution of the final concentration $0.224 \mathrm{mg} / \mathrm{ml}$. Of the standard prepared, $0.2 \mathrm{mls}, 0.5 \mathrm{mls}, 1.0 \mathrm{mls}, 2 \mathrm{mls}$ and $3 \mathrm{mls}$ were each placed into cuvetts and topped to $4 \mathrm{ml}$ using double distilled. Their absorbance was then measured at 510nm using UV-spectroscopy, model PERKIN ELMER LAMBDA $35 \mathrm{uv} /$ vis computerised spectrophotometer double beam. The respective concentrations gave absorbance of $0.098,0.2795,0.4417,0.9907$ and 1.1556. A calibration curve was constructed using absorbance and concentration giving line of best fit in which $\mathrm{R} 2$ value $=0.991$.

\section{Quantification of total flavonoids in artemisia an- nua powder}

Ten (10 g) of dried A.annua of each sample was weighed into a separate conical glass and $100 \mathrm{mls}$ of $80 \%$ methanol then added, coked and allowed to stand for $4 \mathrm{~h}$ with constant shaking to extract flavonids according method previously described by Edeoga et $\mathrm{al}^{14}$. The extractives were filtered using whatmann filter paper (No.1) to obtain clear filtrates. Filtrate $(4 \mathrm{ml})$ was then pipette into $10 \mathrm{mls}$ volumetric flask and $0.4 \mathrm{mls}$ of $5 \% \mathrm{NaNO}_{2}$ add- 
ed, mixed and allowed to react for 6 minutes. A solution of $10 \% \mathrm{Al}\left(\mathrm{NO}_{3}\right) 3(0.4 \mathrm{ml})$ instead of $\mathrm{AlCl}_{3}$ was added , mixed and allowed to complex for 6 minutes before adding $4 \mathrm{mls}$ of $4 \% \mathrm{NaOH}$ to neutralise the acidity. Double distilled water was added to top to the $10 \mathrm{mls}$ mark . For each sample, $2 \mathrm{mls}$ was placed into cuvette and topped to $4 \mathrm{ml}$ using double distilled, its absorbance measured at $510 \mathrm{~nm}$ and total flavonoid concentration estimated from the calibration curve in reference to casticin. The concentrations were used to calculate the total flavonoids content in dry leaf samples as percentage of dry weight.

Quantification of total flavonoids in artemisia annua tea

The tea of A.annua from Wagagai farm and that prepared using powders from Kabale and Fortportal were filtered through what filter paper (no.1). Filtrate (4ml) was then pipetted into $10 \mathrm{mls}$ volumetric flask and $0.4 \mathrm{mls}$ of $5 \% \mathrm{NaNO}_{2}$ added, mixed and allowed to react for 6 minutes. A solution of $10 \% \mathrm{Al}\left(\mathrm{NO}_{3}\right) 3(0.4 \mathrm{ml})$ instead of $\mathrm{AlCl}_{3}$ was added, mixed and allowed to complex for 6 minutes before adding $4 \mathrm{mls}$ of $4 \% \mathrm{NaOH}$ to neutralise the acidity. Double distilled water was added to top to the $10 \mathrm{mls}$ mark. For each sample, $2 \mathrm{mls}$ was placed into cuvet and topped to $4 \mathrm{ml}$ using double distilled water, its absorbance measured at $510 \mathrm{~nm}$ and total flavonoid concentration estimated from the calibration curve with reference to casticin.

\section{Results and discussion}

Major phytochemical groups identified in artemisia annua samples

The qualitative phytochemical test results showed that A. annua from low land and high land areas had similar phytochemical groups including flavonoids and triterpenes (Table 1) the known antimalarial groups. Similarity in phytochemical constituents shows that the A.annua cultivated in the different regions of Uganda are of the same variety.

Table I: Phytochemical groups identified in Artemisia annua samples

\begin{tabular}{lllc}
\hline $\begin{array}{l}\text { Phytochemical } \\
\text { group }\end{array}$ & South western-Kabale & $\begin{array}{l}\text { Western-Fort } \\
\text { portal }\end{array}$ & $\begin{array}{l}\text { Central-Wakiso } \\
\text { (Entebbe) }\end{array}$ \\
\hline Tannins & $(++)$ & $(++)$ & $(++)$ \\
Reducing compounds & $(++)$ & $(++)$ & $(++)$ \\
Polyuronides & $(++)$ & $(++)$ & $(++)$ \\
Saponins & $(-)$ & $(-)$ & $(-)$ \\
Alkaloid salts & $(++)$ & $(++)$ & $(++)$ \\
Anthracenosides & $(++)$ & $(++)$ & $(++)$ \\
Coumarin derivatives & $(++)$ & $(++)$ & $(++)$ \\
Steroid glycosides & $(++)$ & $(++)$ & $(++)$ \\
Flavonosides & $(++)$ & $(++)$ &
\end{tabular}

\section{Aromatic oil constituents in artemisia annua $\mathbf{L}$.}

The major aromatic oil component in all three samples was camphor which constituted more than $75 \%$ of the oils. Camphor has been previously reported as the major aromatic oil component in A.annua cultivated in In$\mathrm{dia}^{15}$ and in Iran ${ }^{16}$. Unlike other aromatic components, camphor and borneol levels did not vary much between the regions (Figure 1). Camphor oil has been shown have mosquito repellent activity and provided up to 97.6\% protection against Anopheles culicifacies ${ }^{17}$.

\begin{abstract}
Artemisinin and total flavonoid contents in powder and teas

Artemisinin content was highest in the sample from Fort portal in Western Uganda followed by that from Kabale in south western Uganda. The total flavonoids in samples from Wakiso in central was about half that from Fortportal and Kabale (Figure 4). These variations call for quality control and standardization of material for not only of artemisinin levels but also of total flavonoids. This is because flavonoids have been shown to play major role in use of A.annua for malaria treatment and prophylaxis ${ }^{4,8,9}$.
\end{abstract}


Figure1: Percentage of Aromatic oil constituents of $A$. annua by region.

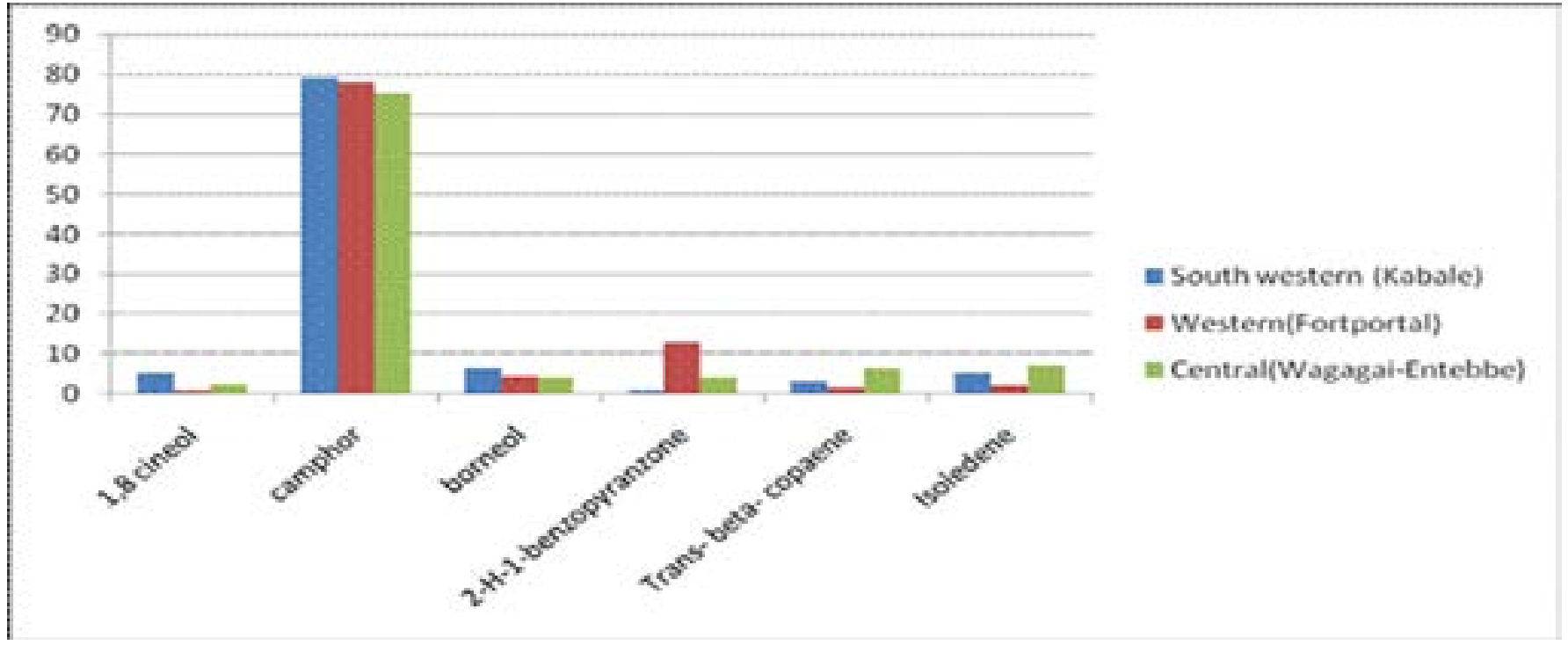

The flavonoids content in Kabale and Fort Portal samples were similar to that previously reported in study on Brazillian A.annua cultivar which had 2.6\% total flavonoid content ${ }^{4}$. The flavonoid contents in A.annua have been shown to vary with stage of growth, with highest amounts found during full bloom just like it is for artemisinin ${ }^{18}$. Although the time of harvesting the A.an- nua was not considered in this present study, farmers in Uganda generally harvest A.annua just before flowering which is the full bloom period. In lowland areas A.annua flowers much earlier than in highland areas perhaps due to higher temperatures and low rainfall compared to high land areas. The variations observed in this study could therefore be associated with the age of the plant at harvesting time.

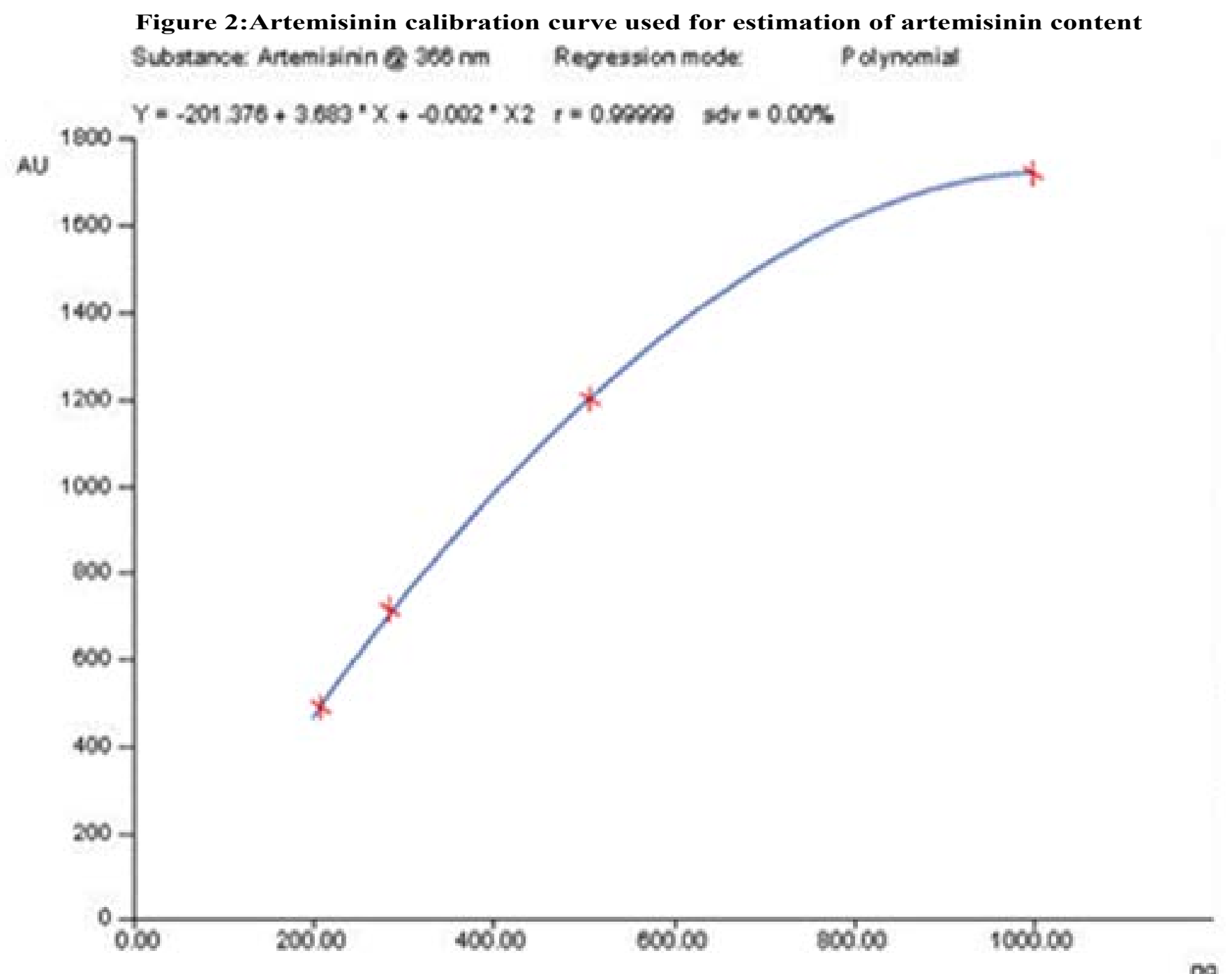




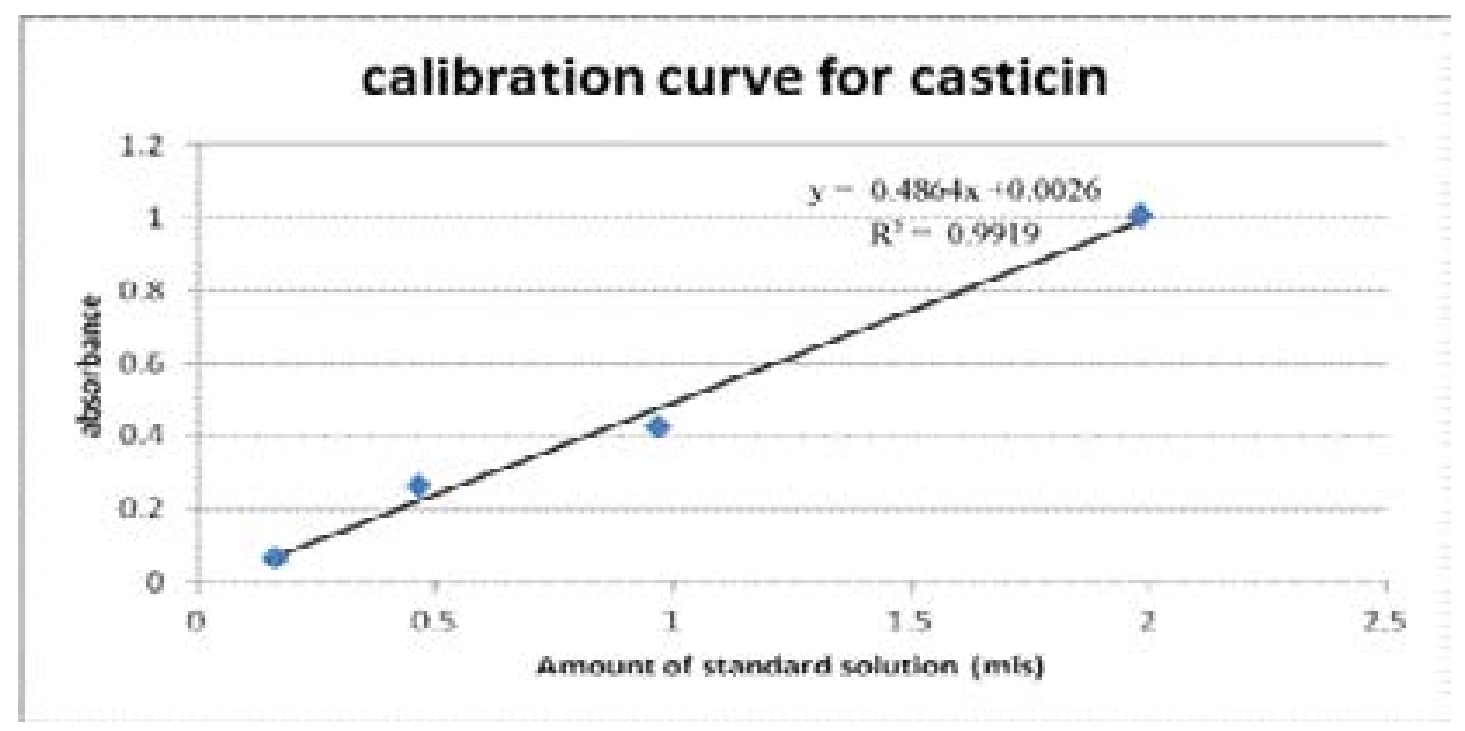

Figure 4: Artemisinin and total flavonoids content $A$.annua powder and teas by region.

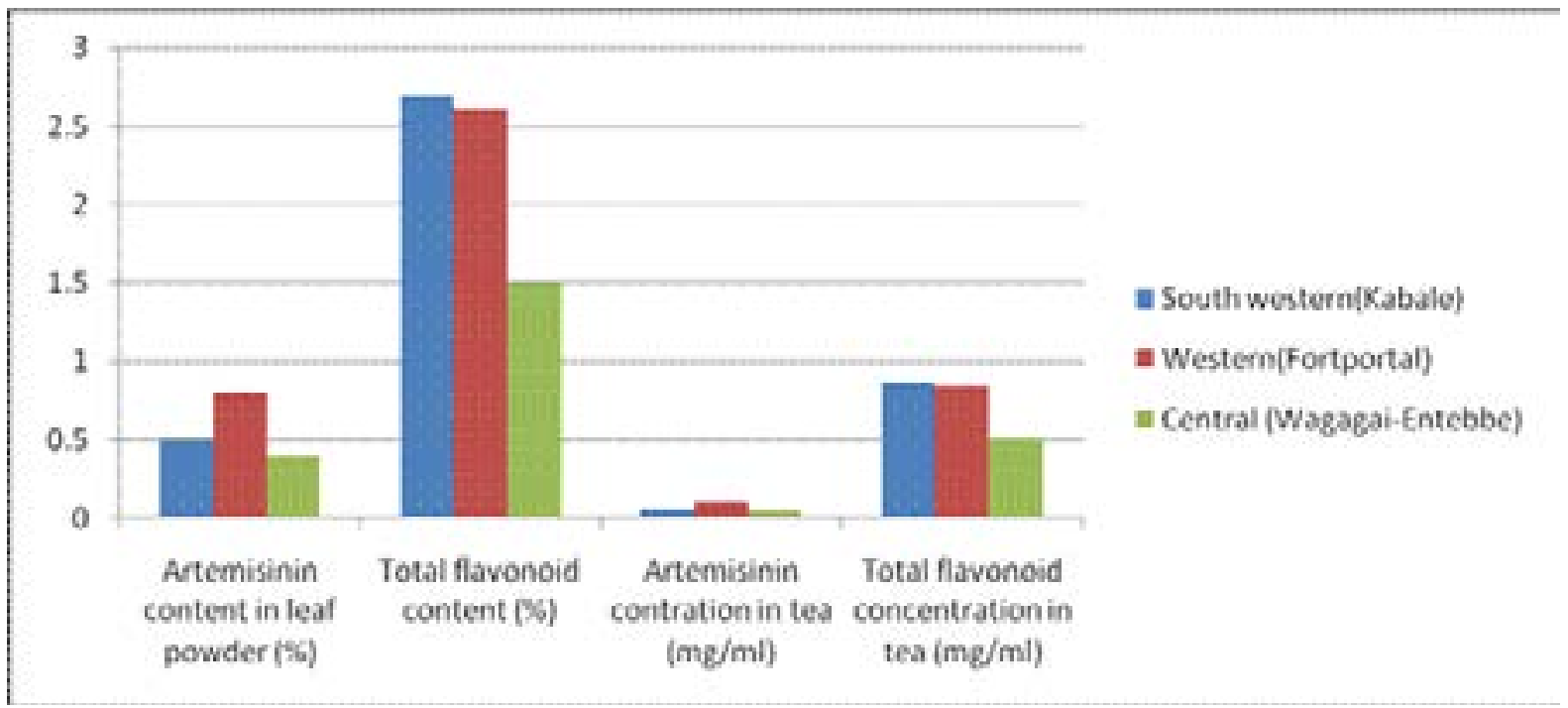

\section{Conclusion}

This study reveals for the first time that the antimalarial components in A.annua vary with geographical area where the plant is cultivated. Standardization by source of A.annua raw materials used against malaria is vital for consistent clinical outcomes. A study on the variation of the components due to the age of the plant visavis geographical location is recommended to enable commercialization of the plant, and effective use by the communities.

\section{Acknowledgements}

Authors thank Ms. Marion Borden, the in-charge Wagagai Health Centre for granting permission to study the Artemisia annnua used in their farm and clinic. Authors are also grateful to the staff of Natural Chemotherapeutics Research Institute and African Natural Products Laboratory in Addis Ababa University Ethiopia for the equipment and technical support rendered especially in the quantification of artemisinin and total flavonoid levels in the A. annua 'tea' and leaf powder used by Wagagai flower farm community.

\section{Financial support}

Authors express their gratitude to the CARNEGIE Corporation through RISE-AFNNET Makerere University node and the Government of Uganda through the Presidential support to scientists under Uganda 
National Council for Science and Technology for the financial support.

\section{References}

1. Willcox M, Bodeker G, Bourdy G, Dhingra V, Falquet J, Ferreira J.F.S, Graz B, Hirt H, Hsu , Magalhães $\mathrm{P}$, Provendier D, and Wright C. Artemisia annua as a Traditional Herbal Antimalarial. Traditional Medicinal Plants and Malaria, Boca Raton, London, New York, Washington DC:CRC press, 2004,pp 43-59

2. Byamugisha T, Byamukama R and Ntale M. Tests confirm suitability of Ugandan soils for commercial growing of Artemisia annua Linn. African Journal of Agricultural Research. 2013;1. 8(37): 4565-4572.

3. Lyda O, Iveth G, Piero O and Walter RJT. Artemisininbased combination therapy for Uncomplicated Plasmodium falciparum malaria in Colombia. Malaria Journal. 2007;6

4. Bhakuni RS, Jain DC and Sharma RP. Phytochemistry of Artemisia annua and the development of artemisinin-derived antimalarial agents. In Artemisia, Wright, C.W., Ed. Taylor \& Francis,London 2002.

5. Bilia, A R, Gabriele C, Bergonzi MC and Melillo DE Malgalhaes. Variation in Artemisinin and Flavonoid content in different extracts of Artemisia annua L. Natural Products Communication.2006; 0: 1-5

6. Jorge FSF, Devanand LL, Tomikazu S and Arne H. Flavonoids from Artemisia annua L. as Antioxidants and Their Potential Synergism with Artemisinin against Malaria and Cancer. Molecules. 2010;15:3135-3170.

7. Rasoanaivo P,Wright CW,Willcox ML,Gilbert B. Whole plant extracts versus single compounds for the treatment of malaria: synergy and positive interactions. Malar J. 2011; 15:10 Suppl 1:S4.

8. Ogwang PE, Ogwal JO, Kasasa S, Olila D, Ejobi F, Kabasa D and Obua C. Artemisia annua L. infusion consumed once a week reduces risk of multiple episodes of malaria: a randomised trial in a Ugandan community. Trop J Pharmaceu Res 2012;13:445-453.
9. Ogwang PE, Ogwal-Okeng J, Kasasa S, Ejobi F,Kabasa D and Obua C.Use of Artemisia annua L.Infusion for Malaria Prevention: Mode of Actionand Benefits in a Ugandan Community. British J. Pharm. Res 2011;1:124132.

10. Wallaart TE. Seasonal variation of artemisinin and its biosynthetic precussors in plants of Artemisia annua of different geographical origin: proof for the existence of chemotypes. Planta Med 2000;66:57-62.

11. Culei I. Methodology for the analysis of vegetable drugs: Practical Manual on the industrial Utilisation of Medicinal and Aromatic Plants.1st ed. Romania: Center Building, 1982.

12. Agarwal SP, Ali A, DuaY and Ahuja S. Determination of artemisinin in bulk and Pharmaceutical dosage forms using HPTLC. Indian J Pharm Sci.2009; 71: 98100.

13. Chen Y, Wang J andWan D . Determination of total flavonoids in three Sedum crude drugs by UV-Vis spectrophotometry. Pharmacogn Mag .2010;6 (24): 259-63

14. Edeoga HO, Okwu DE and Mbaebie BO. Phytochemical constituents of some Nigerian medicinal Plants. African Journal of Biotechnology. 2005; 4 (7): 685688

15. Padalia RC, Verma RS, Chauhan A, Chanotiya CS and Yadav A. Variation in volatile constitutents of Artemisia annua var. CIM-Arogya during plant ontogeny. Nat Prod commun. 2011;6 (2): 239-42.

16. Verdian-Rizi Mohammadreza. Variation in essential oil composition of Artemisia annua L. of different growth stage cultivated in Iran. Botany Research Journal. 2008;1 (2) :33-35

17. Ansari MA and Razdan RK. Relative efficacy of various oils in repelling mosquitoes. Indian J Malariol.1995;32(3):104-11.

18. Baraldi R, Isacchi B, Predieri S, Marconi G, Vincieri FF and Bilia AR. Distribution of artemisinin and bioactive flavonoids from Artemisia annua L. during plant growth. Biochem System Ecol. 2008;36:340-348. 